Doi: $\underline{\text { dx.doi.org/10.17921/2525-5320.2016.289-300 }}$

\title{
O CONCEITO DE EDUCAÇÃO NA GRÉCIA CLÁSSICA: UMA REFLEXÃO SOBRE AS EPOPEIAS HOMÉRICAS
}

Juliana Cristhina Murari Assunção* - UEM

Palavras-chave: Homero. Poesia. Educação.

\section{INTRODUÇÃO}

O presente estudo tem como objetivo discutir o conceito de educação na Grécia Clássica mediante a reflexão sobre a importância da llíada e da Odisseia no processo constitutivo da cultura grega, sobretudo no que se refere ao fenômeno educativo, pois os poemas épicos homéricos são considerados as primeiras obras de literatura grega e os primeiros documentos significativos da história da Educação. $\mathrm{Na}$ medida em que moldavam comportamentos, constituíram-se como meio educador e, embora permeados de aspectos míticos, revelam muito da convivência social grega de então.

Vale lembrar que esse trabalho fundamenta-se nos pressupostos contidos no artigo $1^{\circ}$ da Lei das Diretrizes e Bases da Educação Nacional (1996), o qual se refere à educação como uma prática abrangente dos processos formativos que se desenvolvem na vida familiar, na convivência humana, no trabalho, nos movimentos sociais, nas organizações da sociedade civil e nas manifestações culturais. Neste sentido, a educação engloba os costumes, hábitos e valores, encontrando-se intrínseca em qualquer organização social, já que é fundamental para sua própria construção. Dentro desta perspectiva, visualizar-se-á a educação grega não como uma educação possível e apenas inserida em uma instituição, mas sim, como aquela que se desenvolve nas relações interpessoais de cada indivíduo.

\section{DESENVOLVIMENTO}

\section{A llíada e a Odisseia de Homero}

Na Ilíada, Homero narra à lendária guerra de Tróia, a qual inicia-se com uma 
missão diplomática dos jovens príncipes troianos: Páris e Heitor a Esparta. Lá Páris se apaixona pela rainha Helena, esposa do rei de Esparta: Menelau. Os dois amantes fogem para Tróia às escondidas e, Menelau, com sua honra ultrajada, anseia por vingança. Devido a isso, pede ajuda ao seu irmão Agamenon, rei de Micenas, o maior reino da época, para que o auxilie a recuperar sua linda esposa e a vingar a ofensa que os troianos Ihe haviam feito. Agamenon agrupa então um enorme exército, reunindo guerreiros de diversos reinos dispersos por toda a Grécia e partem para Tróia a fim de travar uma guerra.

Entre as personagens mais significantes do poema está Aquiles, guerreiro e herói, responsável, de certa maneira, pela vitória dos gregos, já que mata o principal príncipe troiano, Heitor. Enquanto o herói se afasta da guerra os gregos são massacrados, mas depois que Heitor mata o seu primo Pátroclo pensando ser o próprio Aquiles, esse retorna à guerra e mata muitos troianos, inclusive o príncipe Heitor.

Um episódio a ser destacado sobre Aquiles seria a visita do rei troiano, Príamo, em sua tenda após ter matado seu filho. Príamo lhe implora que devolva o corpo do filho e Aquiles atende as súplicas do rei e declara trégua para que o príncipe receba as honras fúnebres necessárias.

O essencial, no tocante à Ilíada, é lembrar que o cenário é predominantemente de guerra. Os homens encontram-se em campo de batalha, armados, furiosos, ansiosos por defender uma coisa para eles primordial: a honra. Além disso, os gregos não estavam instalados em habitações estruturadas, mas acampados, vivendo em uma situação precária, adversa, distinta de seu cotidiano. A alimentação é escassa, os níveis de higiene são mínimos, quase inexistentes; estão longe de casa e da família, sendo o cenário predominantemente masculino. As únicas figuras femininas da trama ou são deusas ou são presas de guerra. Com efeito, nesse contexto, os valores presentes são aqueles que favorecem a sobrevivência em uma situação atribulada como aquela: a força bruta e vigor físico.

A Odisseia, por sua vez, conta a saga de Odisseu, herói grego, em sua volta para casa, após 10 anos de guerra em Tróia. Este poema narra às dificuldades que ele enfrenta quando tenta voltar para sua casa em Ítaca, onde o espera sua mulher Penélope, assediada por muitos pretendentes que a querem em casamento para assumir o trono da cidade. No caminho Odisseu se depara com muitos seres míticos, como feiticeiras, ciclopes, sereias, etc. Ele só retorna a sua pátria com o 
auxílio da deusa Atena, que o protege, para que ele revele só algum tempo depois quem ele realmente é. Com a ajuda de seu filho Telêmaco, Odisseu mata os pretendentes e reassume o seu reino.

Aqui o fundamental é que, por mais elementos fantasiosos que apareçam no decorrer da história, seu núcleo é a vida dentro de uma sociedade já desenvolvida, guiada por leis, costumes e hábitos considerados adequados àquela comunidade. $A$ civilidade se faz presente a todo o momento. Exemplos disso são a rainha, que precisa escolher outro marido, ainda que não o queira; a própria estrutura do palácio, que conta com empregados para todos os ofícios; o filho Telêmaco, que precisa estar pronto e maduro para assumir o lugar do pai; e ainda os pretendentes de Penélope, que aspiram ao trono tendo em vista a fortuna e o poder.

\section{A formação histórica da Ilíada e da Odisseia}

É difícil saber de que tempo histórico se trata e compreender de que maneira as relações sociais se desenrolavam nessa ocasião somente com o panorama geral dessas obras. Por isso a discussão sobre esses poemas gregos arcaicos traz como exigência traçar um esboço histórico de como se constituiu o povo grego até a formação da cultura micênica, civilização retratada por essas epopeias.

Os gregos fazem parte de um conjunto de povos denominados Indo-Europeus, que a partir do terceiro milênio a.C. migraram em diversas direções. Alguns deles se direcionaram para a Ásia e outros permaneceram na Europa. Essas migrações proporcionaram a independência dos vários grupos assim constituídos, os quais, como nômades, desenvolveram distintas expressões linguísticas e culturais. No que diz respeito aos gregos e à sua composição, pode-se afirmar que aqueles que habitaram a Hélade e ficaram conhecidos como helenos formaram-se por quatro povos: jônios, aqueus, eólios e dórios. Esses chegaram à Grécia em séculos muito distintos, tendo cada um deles uma organização social e cultural distinta. (ROSTOVTZEFF, 1986, passim)

Dentre esses povos, o que mais nos interessa aqui são os aqueus, que invadiram a Grécia por volta de 1600 a 1580 a.C. Os aqueus dominaram Creta, que era a grande potência política e econômica da época. Os habitantes de Creta, os cretenses, eram o antigo povo jônio e já tinham desenvolvido toda uma organização social, cultural e política, além de consideráveis habilidades marítimas, que lhes permitiram relações comerciais muito significativas. Com a invasão de Creta pelos 
aqueus e a assimilação de sua cultura, origina-se a civilização micênica. O período denominado micênico é uma subdivisão temporal da chamada Idade do Bronze, também conhecida por período Heládico final. Essa cultura desenvolveu-se por volta de 1600 a 1050 a.C. e dominou, econômica e culturalmente, todos os povos do Mediterrâneo Oriental. (BONNARD, 1980).

Com as invasões dórias, por volta do século XII a.C., a civilização micênica foi destruída, houve um retrocesso tanto cultural como social ou econômico, e os aqueus regressaram a Ásia Menor, expulsos pelos seus novos conquistadores.

Segundo afirma Brandão (1997), os aqueus, assim como os jônios e os eólios, voltaram à Ásia como suplicantes, como imigrantes nostálgicos que cultuavam o seu passado de glórias. Mesmo voltando vencidos à terra que seus antepassados conquistaram, esses povos levavam consigo esse sentimento de orgulho referente às antigas conquistas e ao passado cheio de riquezas. Devido a isso, os poemas homéricos tornaram-se fundamentais na vida cotidiana, enquanto instrumentos para incitar à coragem, à esperança e à preservação de valores tradicionais.

Os poemas homéricos eram transmitidos oralmente, os versos da llíada e da Odisseia foram cantados pelos aedos e pelos poetas, geração após geração, reproduzindo os valores fundamentais para aquela comunidade.

Segundo Finley (1998, p.17), "por detrás da llíada e da Odisseia há séculos de poesia oral, composta, recitada e transmitida por bardos profissionais, sem o auxílio de uma só palavra escrita".

Devido a essa oralidade a poesia estava sempre em constante movimento e crescimento, pois cada um que cantava o poema o fazia ao seu particular modo, acrescentando algumas coisas e modificando outras. Brandão afirma (1997) que a poesia micênica não é, de modo algum, estática. Sem o apelo à escrita, sendo somente preservada pela memória, ela se torna suscetível de mudanças.

Nos dizeres de Baldry (1969), a recordação do antigo em conjunção com a necessidade de improvisar um novo material torna-se a característica principal da narrativa de Homero. Outra questão a se considerar diz respeito ao fato de Homero relatar em seus poemas eventos muito anteriores à sua própria época. Encontramse fragmentos de acontecimentos que podem ter ocorrido em meados do século XIII até o século VIII a.C. Assim, nessas epopeias se encontram inúmeros cantos que fazem referência a momentos distintos da história grega, desde um passado glorioso a um presente que se apresenta conflituoso. Por isso é que se contesta a real 
existência de Homero e a legitimidade de suas obras. Ainda que a tradição o tenha adotado como o autor da Ilíada e a Odisseia, há várias dúvidas quanto à sua real existência. Questiona-se se o poeta criou algo novo ou foi só o relator de mitos preexistentes.

Não obstante, a principal questão que se coloca entre os estudiosos - por exemplo, Vico e Wolf - é se teria sido ou não Homero o autor de ambas as obras, pois é visível que a llíada e a Odisseia dizem respeito a períodos distintos da história grega. Independentemente das especulações modernas sobre Homero e a legitimidade de suas obras, sabemos que é com Homero que aparecem os primeiros registros sobre educação, que dão as bases ou a gênese da futura história da Educação.

\section{O conceito de educação grega: a areté heroica}

Quando se reflete sobre a educação na Grécia antiga, não é viável buscar similaridade com o conceito contemporâneo de educação, pois as concepções contemporâneas são muito diversas dos presentes nos tempos homéricos. Devido a isso, é preciso tentar identificar, ainda que aproximadamente, o que os gregos arcaicos entendiam como Educação.

O fenômeno educativo para os gregos não era elaborado e pensado metodologicamente, não tinha nenhuma organização institucional específica. Os ensinamentos sobre aquilo que era minimamente necessário para a vida eram aprendidos em casa, no convívio familiar e com pessoas próximas. Nas relações sociais ensinava-se aos jovens aquilo que Ihes seria imprescindível nas práticas da vida adulta.

Essa forma de educação estava tão presente no cotidiano grego que a sua execução não consistia em uma ação consciente, porquanto se apresentava como natural (JAEGER, 1986).

Importa lembrar que a educação do chamado período homérico não se preocupava com métodos de aprendizagem, mas sim, estava direcionada ao seu fim, ou seja, à determinação da finalidade da educação e aos meios para concretizála. Por isso a preocupação educacional não se dirigia somente à criança, mas também e sobretudo ao adulto que essa criança iria tornar-se. Devido a isso, é impossível considerar os ideais de formação humana entre os gregos sem destacar um conceito fundamental para eles: o conceito de areté. Tal como afirma Jaeger 
(1986, p.18), não temos na língua portuguesa uma tradução exata desse termo, embora seja muito comum traduzi-lo por virtude. Isso, porém, pode levar a pensar que o ideal educacional grego compreendia apenas uma natureza ética, quando na realidade ele ia muito além disso.

O termo que melhor traduziria a areté seria excelência; contudo essa palavra, ainda que expresse preceitos morais, carrega consigo uma multiplicidade de significados que precisam ser abordados, pois é ela que fundamenta o modo de pensar a educação na Grécia pré-arcaica.

Marrou (1998) lembra que o fundamental para compreender as características da educação homérica é lembrar que ela era originariamente privilégio de uma aristocracia de guerreiros. Explica ainda esse estudioso (1998, p.25) que o ideal homérico de formação englobava tanto aspectos técnicos quanto éticos, sendo esses dois aspectos igualmente necessários para a real concretização da educação grega. Quanto aos aspectos técnicos podem ser citadas aptidões físicas, por exemplo, no manejo das armas, nos jogos ou na prática de esportes, e ainda a oratória, a dança, o canto, incluindo a habilidade com os instrumentos musicais. Este aspecto educacional consistia, sobretudo, no treino de atividades práticas definidas, transmitidas e aplicadas pelos mais velhos aos mais novos.

No tocante aos aspectos éticos, é preciso ressaltar que a própria llíada e a Odisseia se constituíram como manuais morais, que ensinavam por meio dos exemplos dos heróis que lá eram apresentados, com vista a criar no futuro um herói guerreiro com determinados valores, atitudes e ideias. Incitavam os jovens a adquirirem virtudes modelares tais como a honra, a bondade, a nobreza, a coragem; e ao mesmo tempo indicavam como deveria ser o comportamento ideal, enaltecendo o gesto de reverência aos deuses, o respeito aos estrangeiros, aos seus antepassados e à sua pátria.

O cerne da ética homérica se fundamenta no valor de cada homem, ou seja, nos méritos ou qualidades pelos quais esse homem se mostra excelente, possuidor da areté. Nessa sociedade guerreira os homens deviam buscar exibir sua areté por meio de atos e palavras, o que implicava que, nas aptidões que lhe eram próprias, o homem devia buscar fazê-las do modo mais perfeito possível, sempre buscando um ideal.

Como afirma Marrou (1998, p.30), o homem grego, não é verdadeiramente feliz senão quando se sente, quando se afirma como o primeiro em sua categoria, 
distinto e superior.

O homem grego tem que sempre desenvolver suas habilidades, para que ele possa mostrar-se superior aos demais, tanto nas olimpíadas quanto na guerra, nas riquezas ou na beleza. Ele procurava se destacar em relação aos demais, sempre buscando a glória, mesmo que, por vezes, tivesse que morrer por ela. A vida do herói se destinava a esse exercício constante de aprimoramento, em que, espelhando-se em uma conduta ideal e desejando provar o seu valor, ele buscava realizar-se como tal, cultivando a honra e buscando a glória.

Uma das formas de mostrar o valor de um herói remete à questão de parentesco. Pertencer a uma determinada linhagem o faz mais ou menos nobre, torna-o, de certa maneira, melhor ou pior. Ter em sua genealogia e entre os seus antepassados, heróis, figuras ilustres, senhores de uma areté admirada, já proporcionava ao homem qualidades e virtudes modelares. O guerreiro devia honrar seus antepassados, procurando ser como estes foram, ou melhor. Na llíada é comumente visível os heróis descreverem a sua linhagem, tentando demonstrar que são nobres, superiores, e principalmente dignos daqueles que enfrentam. guerreiro, ainda que pertencente a uma linhagem ilustre, deveria agir de modo compatível com o esperado para manter a notoriedade de sua família. O guerreiro ideal deveria possuir algumas virtudes essenciais, tais como lealdade, hospitalidade, amizade, coragem e, especialmente, a honra.

A honra é a própria expressão da areté grega, é por ela e por meio dela que os homens asseguram o seu valor. Essa virtude era, entre muitas, a mais grandiosa, e do mesmo modo que os homens buscavam a honra, eles também buscavam ser honrados pelos seus pares. Por isso havia a exigência de respeito mútuo. O desrespeito a essa exigência representava a pior afronta possível, tanto que, para Homero e para o mundo da nobreza desse tempo, constituía a maior tragédia humana (JAEGER, 1986, p.22). A própria guerra de Tróia começou devido à negação da honra. Quando Páris leva Helena para Tróia, ele acaba por ultrajar ferozmente a honra de Menelau, rei de Esparta, o qual, querendo restaurar sua honra, chama seu irmão Agamenon a acompanhá-lo e declara guerra a Tróia.

Outro exemplo do apreço pela honra entre os gregos seria o episódio, narrado no começo do poema, em que Aquiles se retira da guerra por ter sido afrontado por Agamenon quando este se apossa da presa de guerra destinada a ele. A atitude de Agamenon revela uma quebra da tradição: o rei se vale de um poder político tirânico 
para ficar com aquilo que desejava, renegando os valores celebrados por aquela sociedade.

Além dos valores já mencionados pode-se citar como fundamentais para esses homens a hospitalidade e a amizade. Pela quebra da hospitalidade é que Menelau também foi ofendido, já que recebia diplomaticamente os troianos em sua casa quando sua esposa foi levada; e a amizade por Odisseu foi o motivo da própria volta de Aquiles à guerra, para ouvir seus sábios conselhos. Igual amizade ele dedicava a seu primo Pátroclo, morto equivocadamente por Heitor. Embora haja outras virtudes que merecem ser buscadas, as citadas já demonstram aquilo que era esperado no tocante ao comportamento de um homem aristocrata na Grécia desse período. Esse comportamento, idealizado nas figuras míticas heroicas, fundamentava a finalidade da educação homérica: a constituição de um homem completo, excelente em todas as suas aptidões, para cuja concretização o fenômeno educativo concentrava-se no aprimoramento humano e em oportunizar o engrandecimento físico e espiritual.

\section{Semelhanças e diferenças entre a Ilíada e a Odisseia}

Nos mitos homéricos encontram-se personagens de extrema bravura, honestidade, sabedoria e um elevado senso de justiça, do que são exemplos Aquiles, Odisseu e Heitor, os quais se tornaram heróis modelares para os gregos, que deveriam buscá-los como exemplos a serem seguidos. O homem grego aprendia, desde a mais tenra idade, a respeitar os seus deuses e a crer em seus mitos. Esse modelo educativo, que recorria a essas histórias - ainda que fantásticas, objetivava a formação de um cidadão ético, justo e sábio - portanto, do homem aristocrata. Os heróis encontrados na llíada e na Odisseia incorporam as características fundamentais do ser humano da época, do seu ethos.

Justamente por prescrever regras e determinados modos de viver é que os textos homéricos se tornam fenômenos estruturadores da cultura grega, fixando-se como o núcleo da educação daquela sociedade.

Segundo Jaeger (1986, p.44-45), O coração do poeta está com os homens que representam a elevação da sua cultura e costumes, e isso se percebe passo a passo. A contínua exaltação que faz das suas qualidades tem, sem dúvida, uma intenção educativa. [...] A posição e o domínio preeminente dos nobres acarretam a obrigação de estruturar os seus membros desde a mais tenra idade segundo os ideais válidos dentro de seu círculo. A educação converte-se aqui, pela primeira vez, em formação, isto é, na modelação do homem integral de acordo com um tempo fixo. 
Não obstante, é possível perceber certas diferenças estruturais entre os poemas. As diferenças sociais, culturais e políticas são explícitas. A Odisseia, em relação à Ilíada, representa uma posteridade histórica. Isso se faz perceptível na organização social da cidade de Odisseu, nos seus modos, na sua polidez, nos costumes e nas tradições. Um exemplo foi a necessidade de a rainha Penélope escolher um novo marido, já que o seu se encontrava desde muitos anos longe da casa. Em todas as relações interpessoais percebe-se que se trata de um povo já mais refinado e politicamente desenvolvido.

Para Jaeger (1986), o primeiro poema nos apresenta o estado absoluto de guerra, tal como devia ser no tempo das grandes migrações das tribos gregas. A Ilíada representa um tempo em que os valores ideais estavam centrados na coragem e na honra, incluindo sempre a força bruta; já a Odisseia se insere num contexto de paz, retrata o pai e marido que precisa voltar a sua pátria e reassumir o seu papel na família e na sociedade. Enquanto em um momento temos os sentimentos aflorados e o homem guiado sempre pelos seus apetites, no outro esse homem já se encontra desenvolvendo a sua razão, e é por ela que ele está destinado a vencer suas dificuldades. A maior arma de Odisseu é a razão, embora não a razão que seria desenvolvida posteriormente pela filosofia, mas sim, uma razão estritamente ligada à prudência, à engenhosidade, à percepção. Odisseu é astuto e sagaz, e é por meio desses atributos que ele se mantém vivo, como se vê no episódio em que engana Polifemo.

Na llíada, a figura do guerreiro é central. O comportamento do homem não está voltado para a vida pública, em sociedade, mas para suas atitudes na guerra. A figura do herói nesses poemas está sempre inserida em alguma batalha, e o que determina suas virtudes é sua bravura, lealdade, coragem e espírito de liderança. Segundo Jaeger, para o herói a luta e a vitória são a distinção mais alta e o conteúdo próprio da vida.

Os heróis da llíada, que se revelam no seu gosto pela guerra e na sua aspiração à honra como autênticos representantes da sua classe, são, todavia, quanto ao resto da sua conduta, acima de tudo grandes senhores, com todas as suas excelências, mas também com todas as suas imprescindíveis debilidades. É impossível imaginá-los vivendo em paz: pertencem ao campo de batalha. Fora dele só os vemos nas pausas do combate, nas suas refeições, nos seus sacrifícios, nos seus conselhos (JAEGER, 1986, p.41). 
O cenário dos poemas é sempre repleto de lutas, em que o mais valente é também o mais respeitado por todos. Pode-se dizer que esse modelo é reflexo da vida daquele tempo e corresponde historicamente a um período em que a civilização ainda não estava consolidada; o homem dessa época se via constantemente em guerra e as tribos migravam sempre e lutavam entre si.

$\mathrm{Na}$ Odisseia encontra-se um cenário efetivamente diferente. Como já mencionado, quando Odisseu aparece como um rei, um marido e um pai que deseja regressar à sua casa, nota-se o seu refinamento e o dos pretendentes de Penélope. Por suas manifestações culturais - como o comer, o beber, o cantar ou celebrar percebe-se quanto o mundo grego já estava evoluído. O homem, inclusive na figura do herói, está muito mais centrado em sua casa do que na guerra. Agora ele tem uma terra natal, fixa, onde vive e adquiriu e cultua muitos costumes, como as libações que deve fazer aos deuses, o respeito à tradição ou o que se constata no caso da rainha que teve obrigatoriamente de escolher um novo rei, já que Odisseu estava ausente havia mais de vinte anos. O homem se vê dentro de uma cidade, de uma comunidade onde prevalecem leis jurídicas e regras morais.

Na Ilíada há o herói na batalha, na Odisseia ele aparece depois desta. Diz Jaeger:

A nobreza da Odisseia é uma classe fechada, com intensa consciência dos seus privilégios, do seu domínio e dos seus costumes e modos de vida refinados. Em vez das grandiosas paixões das figuras sobre-humanas e dos trágicos destinos da llíada, deparamos no novo poema com grande número de figuras de estatura mais humana (JAEGER, 1986, p.43).

Nesses dois poemas algumas questões expressam-se de forma significativa: há aqui uma passagem do "primitivo" para o já "civilizado", em que o guerreiro é substituído pelo cidadão polido. Homero, ao ressaltar as características do herói enquanto força bruta na Ilíada e astúcia na Odisseia, mostra sua preocupação e o objetivo da sociedade em dois momentos diferentes. A clara mudança do predomínio do espírito guerreiro para o de cidadão revela um desenvolvimento dentro de um determinado período histórico, apontando para um diferente ideal de homem.

Homero, tal como afirma Platão (República: livro X, 606C), foi o educador primeiro da Grécia. Ele guiou durante muitos séculos o modo pelo qual os jovens deveriam se comportar e o que deveriam aprender para estarem prontos para a vida 
em um ambiente coletivo. Mesmo depois de a Grécia procurar sobrepor ao pensamento mítico o pensamento filosófico, o homem grego ainda recorria aos poemas para idealizar modelos de virtude, justiça e coragem. Quando se procura mostrar homens dignos e merecedores de glória, ontem como hoje, recorre-se às figuras heroicas - como Aquiles e Odisseu no passado e as personagens marcantes de hoje.

\section{CONCLUSÃO}

Apesar das diferenças estruturais constatadas na llíada e na Odisseia pode-se concluir que, por meio dos mencionados poemas organizou-se o ideal pedagógico da Grécia, criou-se um ideal de homem e pensou-se uma espécie de modelo de guerreiro heroico que deveria ser seguido por todos os homens. A educação homérica consistia principalmente em perseguir esse ideal guerreiro. Quando o jovem procurava ser igual ao herói representado e almejava ter as mesmas virtudes de que esse herói era portador, ele era educado. Para ter valor e se destacar entre os seus, ele tinha que pertencer a uma linhagem notável, honrar sua família, sua pátria e seus pares; deveria ser hospitaleiro, amigo, justo e bom, além de corajoso, astuto e viril. Deste modo, envolvendo tanto os aspectos práticos quanto os morais, essa forma de educação objetivava desenvolver o homem na sua completude, fazendo-o alcançar os mais altos níveis de suas aptidões próprias e oportunizando que ele fosse excelente: senhor da areté.

Esse modelo de homem completo influiu em todo o pensamento ocidental e perpetuou-se até a contemporaneidade. O modelo criado por essa literatura foi usado para educar o homem grego ao longo dos séculos, e até hoje os heróis presentes nos mitos são buscados quando se precisa de um exemplo de homem completo, verdadeiro, portador de todas as características que compõem o homem perfeito, ideal. Por meio de uma educação não preconcebida, mas poeticamente empregada, os mitos ajudaram a formar homens com qualidades tais, que talvez nem mesmo a educação de hoje, tão articulada e formulada, seja capaz de fazê-lo.

\section{REFERÊNCIAS}

BALDRY, B.C. A Grécia Antiga: cultura e vida. Lisboa: Verbo, 1969.

BONNARD, A. A civilização grega. Lisboa: Edições 70, 1980. 
BRANDÃO, J.S. Mitologia Grega. Rio de Janeiro: Vozes, 1997.

FINLEY, M.I. O legado da Grécia. Brasília: ed.UnB, 1998.

FINLEY, M.I. Os gregos antigos. Lisboa: Edições 70, 1963.

HOMERO. A Odisseia. São Paulo: Ediouro, 2004.

HOMERO. Ilíada. São Paulo: Tecnoprint, s/d.

JAEGER, W. Paidéia: a formação do homem grego. São Paulo: Martins Fontes, 1986.

MARROU, H.-I. História da educação na antiguidade. São Paulo: EPU, 1990.

ROSTOVTZEFF, M. História da Grécia. Rio de Janeiro: Guanabara, 1986. 